\title{
Book Review: Directions of Development of Public Administration in Poland
}

\section{Aleksander Jakimowicz ${ }^{1}$, Lech Nieżurawski}

Reflections on the sidelines of the book by Daniel Rzeczkowski (2014), Potencjał Innowacyjności Sektora Administracji Publicznej [Innovative Potential of the Public Administration Sector]. Warsaw: Wydawnictwo Naukowe PWN. Pages 164. ISBN, EAN: 9788301174590.

The cognitive purpose of Daniel Rzeczkowski's book is the explication of the reasons of a gradual decline of Poland's position in the international ranking of innovativeness of the e-Government sector. The ranking is prepared every two years by the UN. According to the basic claim of the work, that objective cannot be achieved without transition to a local level and explaining how the public sector of administration works, and how it functions at the level of communes. This entails using case study as one of the basic research methods. The reasons for the selection of the Warmia-Masuria Province have been made clear in the work. The research hypotheses assumed by the author have inclined him to undertake research on human capital resources on a wider scale in the above-mentioned province. On the one hand, the web pages of commune offices, and the bulletins of public information placed there, are evaluated as potential innovation carriers and, on the other, what we have here is a unique attempt at the identification of systematic errors in the process of public services rendering. In connection with the latter, the author refers to the hypothesis of rational expectations. The research issue raised in the work should be regarded as non-trivial and practical. Also, the innovatory approach consists in proposing methods of comprehensive evaluation of the public administration sector at the level of communes. Besides, the book has certain theoretical advantages. The conclusions drawn

\footnotetext{
1 Aleksander Jakimowicz, Professor at the Institute of Economics, Polish Academy of Sciences, Staszic Palace, 72 Nowy Świat St., 00-330 Warsaw, Poland, e-mail: ajakimowicz@inepan.waw.pl

2 Lech Nieżurawski, Professor at the WSB University in Torun, 31 a Mlodziezowa St., 87-100 Torun, Poland, e-mail: I.niezurawski@wsb.torun.pl
}

Received 22 June 2018; Accepted 30 July 2018. 
on the basis of the empirical research have allowed the author to propose development of such a model of perception gaps, in which local and central multimedia customer service offices would become a mechanism for the elimination of the gaps.

The work, constituting the subject matter of the present discussion, consists of the introduction, the contents, seven theoretical-empirical chapters, the conclusion and the bibliography. In the first chapter, the reasons for undertaking the research, the objectives, the scope of research work, the research hypotheses and the applied methodology are presented. The author has undertaken an extremely important and, at the same time, challenging task of explicating the reasons for the systematic decline of the Polish public administration sector's innovativeness. The search for a comprehensive method of evaluation of the e-Government sector at a local level and an attempt at an identification of innovativeness in the customers of public administration communal offices, indicate the genuineness of this study. In the research proceedings exemplification was used, which allowed the author to fluently shift the considerations from an international to a local level in order to "point out the factual gaps in the system of public services rendering in this region" (p. 10) in the example of communes and of the condition of human capital in the Warmia-Masuria Province. The logical structure of the work presented in this chapter involves the separation of three pillars of research - two empirical and one theoretical. The first empirical pillar covers the research on the quality of public services rendered online. It involved the application of an analysis of focuses on the evaluation of the communal office's web pages and public information bulletins found there. The second empirical pillar involved the evaluation of human capital in the region in question and the application of the principle of correspondence analysis for the purposes of the detection of the systematic errors occurring in the processes of communication between a civil officer and a customer. The theoretical pillar refers to service quality models and processes of reduction of the perception gaps predicted by these models. Here, once again, the innovatory character of this work shows that, since the proposed-by-the-author multimedia services office, whose design is discussed later in chapter seven, it turns out to be the searched-for mechanism of gaps reduction. Integration of all the themes of this work, empirical and theoretical, has provided a basis for the elaboration of a synthesis, consisting in formulating indications aimed at raising Poland's position in the UN's ranking, thus specifying the necessary conditions for triggering the innovativeness potential inherent in the people entering into interaction with the public administration sector.

One of the advantages of this work is making a reference to wikinomics - a new school of economic thinking based on four principles: openness, 
peering, sharing, and acting globally (Tapscott and Williams 2006 2012). Wikinomics is based on seven non-standard business strategy patterns: peer pioneers, ideagoras, prosumers, new Alexandrians, platforms for participation, a global plant floor, and a wiki workplace. The author applies these patterns in his empirical research, which becomes particularly evident in chapter six, where the evaluation of the prosumptive potential of the innovativeness occurring in the public administration sector was carried out. Among the author's interesting achievements, the elaboration of a genuine measure of innovativeness potential should also be mentioned; one applied to the evaluation of the communal sector of public administration. It is based on both the UN standards of public sector innovativeness and on some selected wikinomic ideas. The measure takes into consideration economic phenomena. On the one hand, it indicates the necessity to treat the communal public administration offices web pages as platforms for participation (in the sense of the wikinomics) and on the other, it proves that the triggering of prosumption processes is an adequate method of managing the natural creativeness and innovativeness of offices' customers. The innovativeness potential measure, presented in this work, utilizes thirteen qualitativequantitative criteria evaluating the functioning of public administration communal offices from the angle of both supply and demand.

The second chapter is devoted to a detailed discussion of the methodology applied in the evaluation of e-Government systems in the particular countries. Here, the construction of the E-Government Development Index and its components: the index of services provided online, the coefficient of the telecommunication infrastructure and the coefficient of human capital, is clearly explained. In the final part of chapter two, the changes in Poland's position in the international E-Government Development Index Ranking in the years 2008-2012 are shown against the background of central-eastern European countries. It turns out that the stagnation in the development of the public administration sector has taken place in the whole region except for Russia and Moldavia, where very rapid improvement has been observed. That would suggest the possibility of exploitation of the solution developed by the author for the Warmia-Masuria Province, not only in the other regions of Poland but also in neighboring countries. The correctness of this line of reasoning follows from the existence of the common ground of the stagnation of the public administration sector in the region in question. Thus, the research proceedings are exhaustive as they began with the exemplification leading from global macroeconomic issues to local problems, and were concluded with a synthesis which leads from the level of Polish communes to an international level. The author is perfectly aware of the inadequacies of UN methodology. Adequate as it is for the purposes of macroeconomic 
analysis and international comparisons, it fails at a local level when Polish communes are concerned. Hence, there occurred a need to develop a suitable measure of innovativeness potential, which could take into consideration the specificity of public administration communal offices. As has already been pointed out above, the author has lived up to that task perfectly.

In chapter three, selected issues pertaining to the quality of public administration sector services are raised. After a brief discussion about the necessity for adjustment of the quality of public sector services to the standards pertaining in the private sector, the author discusses the Gummesson $4 Q$ model of offering quality, one which takes into consideration four types of quality: of the design, of the production and delivery, of the relationship and of the result. This model has provided valuable guidelines, which were used in the empirical studies presented in the further sections of this work. In the chapter in question, the model of perception gaps was also included, which is particularly useful in the public sector. The sources of these gaps are the divergences between people's expectations concerning the functioning of public administration offices and the authentic condition of these offices. A relatively interesting problem raised in this chapter is pointing to the possibility of explication of perception gaps on the basis of the hypothesis of rational expectations, familiar in economics. It allows one to interpret these gaps as a result of systematic errors occurring in the communication processes between a customer and a civil officer. Such an approach was support for the practical evaluation of the prosumption innovativeness potential, which was performed in chapter six. Another remarkable contribution made by the author is the use of a modified matrix of importance-performance for the interpretation of the results provided by the maps of correspondences.

Chapter four contains a general description of the Polish e-Government sector. The legal grounds of this sector's functioning were indicated, the Electronic Platform of Public Administration Services (e-PUAP) was characterized and the elements of the long-term strategy, aimed at the implementation of the idea of open office, were listed. While assessing the condition of e-services in the last decade, the author discovers that, in spite of its initial successes, we are nowadays facing stagnation in the growth of the e-Government sector, as only a very small number of public services are fully available online.

In chapter five, the author undertook the challenging task of examining the evaluation of the quality of public services rendered online by communal public offices in Warmia-Masuria Province. The research focused not only on determining the extent to which customers' needs are met but also on describing the ability of offices to exploit the innovation potential of the 
users. The criteria for the evaluation were developed in such a way as to take into consideration both the proposals of the prosumer approach, postulated by wikinomics and e-Government ideas. The methodology applied here is adequate for this type of task. The communal web pages were evaluated in accordance with the standards of the WAES system (Website Attribute Evaluation System), i.e. a multi-criteria system of evaluation of online services involving the binary method. Next, using the k-means method, the clustering of communes was performed by dividing them into four groups, depending on the quality of their websites (low, average, high and very high). Similarly, the quality of communal public information bulletins was assessed. The scores obtained by the particular offices depended on the online availability of the information concerning each of the offered public services, and also on the fact of attachment or non-attachment of suitable forms to each of them. The scores were assigned using the binary system - either a given feature was present or not. As before, the clustering of communes was performed using the k-means method. They were divided into four groups, depending on the quality of their bulletins of public information (low, average, high and very high). The clustering of communes into wealth categories from the point of view of the online services and public information bulletins run by them is a very important cognitive tool, both from the theoretical and the practical point of view. Indeed, not only does it allow for an adequate qualitative description of the phenomenon under study but it also defines the tasks that each commune has to face, indispensable to unlock its supply- and demandrelated factors of innovation.

As far as the evaluation of the web pages and public information bulletins is concerned, the research consisted of two stages. The first stage of the research was carried out in 2009, whereas the second was in 2012. In this way, the analysis does not have a static nature, it is not limited to only one point in time, but it is dynamic and long-term. The intertemporal comparisons have established that communal offices of public administration are constantly aiming at quality improvement of their websites, but the progress in this field is still unsatisfactory. The author emphasizes the fact that communes are aware of the necessity for a fuller satisfaction of customers' needs. It can be best seen in the example of services such as access to archives, where language versions other than Polish are made available, or assistance in navigating through the site. However, the road to a new type of administration postulated by wikinomics and the UN is still very long. The situation with mailing lists for citizens and possibilities of submitting forms electronically is not much better. It follows from the studies that the progress in the sphere of quality improvement in the communal public information bulletins is a little faster; however, it concerns only the first ten criteria. The scores for public consultancy, surveying clients, 
service cards and states of affairs, however, are very low. One of the advantages of the chapter is the maps showing the spatial arrangement of communes belonging to the groups, determined by the quality of their websites and by the quality of their public information bulletins.

Chapter six, which is mainly empirical, starts with a discussion about a relatively new category in economy - prosumption, on which wikinomics is based. The essence of prosumption is the blurring of distinctions between the classical producer and the consumer by including the latter in the processes of designing, creating and producing goods and services. In accordance with the principles of wikinomics, the development of prosumption processes - based on social networks - is inevitable, as it is the only way to unlock the customers' potential of innovation and creativity and is also an effective method of lowering the costs of research-development studies in enterprises. However, this calls for a change in the traditional business model of firms and for handing over some part of the control over a product or service to the prosumer communities. These changes are not only limited to the private sector but are increasingly the more frequent concern of the public sector. The objective of chapter six is to evaluate the prosumption potential of innovation which could be used by the public administration bodies of a selected province. In this research, the method of a questionnaire survey was used. It helped identify the needs and conditions of servicing the clients and the communication processes between a customer and a civil officer, as well as determining customers' preferences and expectations. The respondents were adult residents of the province who had been clients of the office at least once. The sample should be considered representative. The estimation error was at a level of $3 \%$, with a confidence ratio of 0.95 , which pointed to the sample number being not smaller than $N=1067$. This condition was fulfilled. The representativeness of the results was increased due to the application of post-stratification of data.

For the purposes of evaluation of the study results, correspondence analysis was applied, whose use had been preceded by statistical verification of numerous hypotheses, crucial from the angle of the research objectives. Making use of the co-existence of phenomena, a segment of customers carriers of the greatest innovation and creation potential - was determined. Taking into consideration such criteria as a professional career or their household's development, they were either people starting out in life or people with a stable position in society. They declared a readiness to create prosumer social networks supporting the development of public administration; however, unfortunately, their potential has not been exploited so far. In the chapter in question, the hypothesis of rational expectations was also exploited in order to identify the systematic errors occurring in 
the processes of interpersonal communication between civil officers and their clients. The proposed-by-the-author transition from the basic activity of public administration offices to the network may bring two kinds of advantages. Firstly, it may help use the natural creativity of people from the public sector which would, however, require not only access to the Internet but also a change in the model of public services rendered in the direction of the society's greater participation in the resources and databases (partner system). Secondly, the sources of irrationality, widely analyzed in this work, may get neutralized by the very act of offices placing most of their activity on the Net. According to the author, the hypothesis of rational expectations in combination with prosumption provides a possibility to realize the basic ideas of e-Government.

In chapter seven of this work, the project of a multimedia customer servicing office is presented, one resulting from both the theoretical considerations and from those conducted in the previous chapters. It is the crowning glory of the research, a synthesis consisting in combination of all the themes of the work in one consistent piece. Here the supply- and demandrelated methods of unlocking the innovation potential of public administration are indicated. The most important initiatives pertaining to the supply side are the changes in the state's information and servicing structure. It particularly concerns the e-PUAP system, which - in accordance with the principles of wikinomics - requires changes involving its transition to a social platform of participation and innovation. It would allow the state to share quickly and efficiently its information resources with its citizens, entrepreneurs and other public administration units. Multimedia customer servicing offices would be very helpful in the realization of these ideas and they should operate both at a local and central level. They would constitute a valuable addition to the e-PUAP system. Unlocking the innovative potential on the demand side requires actions aimed at the popularisation of prosumption attitudes and the implementation of social networking websites as indispensable elements of the process of public services rendering.

The detailed solutions concerning the provision of the particular public services, accepted in the multimedia customer service offices, should take into consideration the specific character of these services. There should be as many detailed solutions as the number of public services made available online. For this reason, in chapter seven, a reference was made to a case study and the present functioning of one of the most complex public services in Poland - a service involving obtaining a decision concerning building development conditions - was compared with its multimedia solution. For this purpose, diagrams were made identifying the users of a particular kind of service, the bodies participating in the decision-making process, the specific 
administrative procedures connected with obtaining a decision concerning building development conditions, as well as suitable maps of the activity involved in the process. As a result, it turns out that the multimedia solution is the best way of implementing the technological and organizational progress in the public administration sector and it does not involve any additional legislation, such as changes in the administrative law.

In conclusion, a reference to the realization of the research goal was made and it was shown that it had been achieved. All four research hypotheses have been positively verified. Also, the necessary conditions for getting the Polish public administration sector out of the state of stagnation in which it is now immersed were formulated.

While reading the work, certain critical comments also come to mind. The first one concerns the lack of a consistent approach to the hypothesis of rational expectations. The reader may have an impression that rational expectations are understood by the author in terms of Muth's conception ( $p$. 107), and so the condition of rationality would consist in the compatibility of the subjective expectations of public administration offices clients with a suitable economic theory. At the beginning everything is correct and, in the present case, the theory in question is the public services model discussed in chapter three, the one which takes into consideration the wikinomics prosumption postulate and the main assumptions of e-Government. However, the model considered in the work has distinctly the character of a pattern, and so rationality is understood, in fact, as the degree of accordance of the expectations with this model, and so finally as the degree of reduction of perception gaps predicted by this model. By the same token, what we have in this book is to do with rationality tied to a system of values, where it is a continuous variable which may assume values from a certain interval. As it is a relative feature, its natural interval of changeability should be the open interval from $0 \%$ to $100 \%$. The extreme values should be omitted as unreal. Thus, what we have here is a certain system of partial rationality. Consequently, a departure from the traditional stream of research on the hypothesis of rational expectations has taken place.

The author begins his studies on expectations in the classic way and makes use of the direct method of observation of the expectations. In order to collect the data he applies a qualitative survey research and during the data analysis he notices the equivalence between the method of Gourieroux and Pradel's (1986) contingency tables and the applied-by-himself correspondence analysis (p. 13). During the next stage of the analysis, however, he quits the classic methods of studies on rationality and foregoes the standards of the expectations rationality tests in favor of determining the co-existence of phenomena. Such proceedings should be regarded as appropriate since 
it had resulted from the non-traditional views on rationality, in which it is understood as a certain kind of distance of the factual condition from the pattern. In this approach, a consolidation of a certain state of irrationality (or of a low level of rationality) is a systematic error - constituting the equivalent of a gap in the public services model - in spite of the fact of undertaking attempts at its elimination. This issue is an attempt at a new approach to the rationality of expectations of the clients making use of a very specific kind of services, namely public services. That is why it should have been discussed in detail in the book and the reader may feel dissatisfied with this connection.

The author should have expanded to a greater extent the methodological part and noted that the theory of graphs (networks) provides alternative methods of examination of the issues raised in this work. Their application could help clarify the considerations, in spite of the fact that these methods correspond to some extent to correspondence analysis. Indeed, the subject matter of his studies is the bipartite graph, whose nodes belong to two disjunctive sets and no edge connects the nodes from the same set. The nodes are the units under study, namely the set of public administration offices and the set of their clients, understood as physical persons and entrepreneurs, whereas the interactions between them are represented by the edges. Therefore, the interaction inside the set of offices and inside the set of clients is not taken into consideration. In such an approach, it immediately transpires that only the cases of G2C (government to citizen) and G2B (government to business) are under examination, while the case of G2G (government to government) was omitted in the work, although it would have followed from the declaration in the first chapter (p. 12) that it would be considered.

Tapscott and Williams (2006), in their book on wikinomics, encourage the readers to add subsequent chapters to it since this new science, characterized by a non-standard perception of management processes, is only in the making. The book by Daniel Rzeczkowski meets that challenge since it constitutes a successful attempt at combining the basic ideas of prosumption with the conceptions of e-Government and their practical application.

\section{References}

Gourieroux, C., \& Pradel, J. (1986). Direct test of the rational expectation hypothesis. European Economic Review, 30, 265-284.

Tapscott, D., \& Williams, A. D. (2006). Wikinomics: How Mass Collaboration Changes Everything. New York: Portfolio.

Tapscott, D., \& Williams, A. D. (2012). Macrowikinomics: Rebooting Business and the World. New York: Portfolio/Penguin. 
